www.jmscr.igmpublication.org

Impact Factor (SJIF): 6.379

Index Copernicus Value: 71.58

ISSN (e)-2347-176x ISSN (p) 2455-0450

crossref DOI: https://dx.doi.org/10.18535/jmscr/v6i5.121

Journal Of Medical Science And Clinical Research

\title{
Pulsed Doppler Imaging of Ophthalmic and Central Retinal Arteries in Diabetics with and Without Retinopathy and Controls
}

\author{
Authors \\ Sahadevan Vijay ${ }^{1}$, Siddarth Ragupathi ${ }^{2}$ \\ ${ }^{1}$ Assistant Professor, Christian Medical College, Vellore \\ ${ }^{2}$ Assistant Professor, Vinayaka Mission Research Foundation, Karaikal \\ Corresponding Author \\ Siddarth Ragupathi
}

No.10/25, Banadurai South Street, Kumbakonam - 612001, Mobile: 9952529898

\begin{abstract}
Aims and Objective: The aim of this study is to evaluate hemodynamic changes of ophthalmic artery and central retinal artery in diabetic patients with and without diabetic retinopathy by comparing it with normal individuals and to find the use of pulsed Doppler imaging in differentiating diabetic patients with retinopathy from those without retinopathy

Materials and Methods: Sixty patients, divided into three groups twenty each as non-diabetic controls, diabetes without retinopathy and diabetics with retinopathy. All the patients underwent pulsed doppler imaging through ultrasound modality. We qualitatively analysed the values of velocities and RI in ocular vessels.

Results: There was a statistically significant $(p<0.001)$ decrease in both the peak systolic velocity (PSV $0.10 \mathrm{~m} / \mathrm{s})$ and end diastolic velocity $(E D V 0.02 \mathrm{~m} / \mathrm{s})$ of the central retinal artery in the diabetic patients with retinopathy compared to the diabetic patients without retinopathy (PSV $0.12 \mathrm{~m} / \mathrm{s}, E D V 0.03 \mathrm{~m} / \mathrm{s}$ ) and the control group (PSV $0.14 \mathrm{~m} / \mathrm{s}, E D V 0.04 \mathrm{~m} / \mathrm{s})$. The peak systolic velocity and resistance index of the ophthalmic artery was significantly increased in both groups of diabetic patients with retinopathy (PSV0.35, RI-0.80) and without retinopathy (PSV-0.34, RI-0.77) compared to controls (PSV-0.31, RI-0.71)

Conclusion: Pulsed Doppler imaging is a useful modality to assess the risk of developing proliferative diabetic retinopathy which can lead on to visual loss. There was significant decrease in blood flow velocity of CRA of diabetic patients and it was much more reduced on comparing it with diabetic patients with retinopathy. The RI values of ophthalmic artery were also found to be increased in diabetic patients. Although the assessment of orbital blood flow in retinopathy requires further investigations, based on the results of our study we suggest pulsed Doppler imaging for its ability to provide information about hemodynamic changes and for the diagnosis of diabetic retinopathy as a supportive modality.
\end{abstract}

\section{Introduction}

One of the vascular disorders that affect the retinal microvasculature is Diabetic retinopathy. It is estimated that some form of diabetes affects 8.3 percent of the world's population, almost half of are associated with some degree of diabetic retinopathy at any given time ${ }^{[1]}$. Both type I and type II diabetes mellitus patients show occurrence of diabetic retinopathy according to early epidemiological studies on long standing upto 15 
years. It has been known that nearly $80 \%$ of type one and $85 \%$ of type two diabetic patients develop diabetic retinopathy ${ }^{[2,3]}$. The world health organization (WHO) has reported India has been showing epidemic increase in type II diabetes mellitus ${ }^{[4]}$, and it is one of the fast progressing cause of visual disability is diabetic retinopathy. The severity of hyperglycaemia is considered as the key risk factor for developing retinopathy. Along with this duration of diabetes is known as the next possible risk factor. The introduction of orbital colour Doppler imaging (CDI) in 1989 by Erickson et al. presented the opportunity for assessment of orbital blood vessels and to see the vessel changes. Doppler imaging is a non-invasive method to assess the blood flow velocities and resistive index qualitatively and quantitatively through ultrasound. Orbital vessels may easily be identified because the Doppler shift is encoded in colour and is superimposed on the two dimensional, gray-scale ultrasound image. Thus, even vessels below resolution of a gray-scale image can be visualized. In this way, the circulation of the ophthalmic artery (OA) and central retinal artery (CRA) may be investigated. With very few studies performed on this topic outside India to our knowledge, in our study we aim in better characterization of orbital circulation in diabetic patients with and without retinopathy and compare it with normal subjects.

In India, diabetic retinopathy is liable to pose a public health burden due to its possibility of occurrence among the large number of diabetic subjects. As visual loss is being the end stage severe condition occurring in long standing cases, we look to provide a better modality to evaluate the progressive changes and help the patients with adequate anti-diabetic treatment to prevent further vascular damage and improve their quality of life with timely intervention

\section{Aims \& Objectives}

1. The aim of this study is to evaluate hemodynamic changes of ophthalmic artery and central retinal artery in diabetic patients with and without diabetic retinopathy by comparing it with normal individuals

2. To find the use of Pulsed Doppler imaging in differentiating diabetic patients with retinopathy from those without retinopathy

\section{Materials and Methods}

This was a prospective study, which was conducted at the Mahatma Gandhi Medical College and Research Institute Hospital, a rural tertiary care hospital with an annual volume of above 1,00,000 patients over one year period. The Institutional Medical Ethics Committee approved this study. All the known cases of diabetes with and without signs of diabetic retinopathy and those without diabetes (controls) were referred for Pulsed Doppler imaging from ophthalmology and those willing to give consent were included in this study. MINDRAY DC-8 ultrasound machine was used throughout the study with $7.5 \mathrm{MHz}$ and $3.5 \mathrm{MHz}$ probes for examining CRA and $\mathrm{OA}$ respectively.

A TOTAL OF 60 Patients were involved in this study (MALE-31, FEMALE-29). An informed consent was obtained from every patient. Normal adult patients $>18$ years of age of both males and females having normal blood glucose and normal blood pressure levels volunteering for the study and diabetic patients with duration of disease from 2-15 years, those with and without manifestations of diabetic retinopathy clinically were included in the study.

Those not willing to give consent and those with history of smoking and other conditions such as congenital orbit pathology, trauma, infections or inflammatory lesions, benign or malignant lesions in orbit and cerebrovascular insult or CVA, hypertension/ dyslipidaemia, glaucoma and any intraocular surgery were excluded.

Around 20 adult patients as known case of diabetes mellitus with fundoscopic examination showing features of diabetic retinopathy, 20 patients with diabetes mellitus without diabetic retinopathy and 20 normal volunteers were used. 
The diabetic subjects were prospectively from the ophthalmology department in our institute.

Initially, after obtaining consent from the patient, they were divided into three separate sub-groups controls, diabetics without diabetic retinopathy and diabetics with diabetic retinopathy. The diabetic subjects were categorized following dilated fundoscopy using the biomicroscopic indirect ophthalmoscope by a single experienced medical ophthalmologist. Doppler imaging was performed on ophthalmic artery (OA) and central retinal artery (CRA) by using the Mindray machine with 7.5 and $3.5 \mathrm{MHz}$ probe. Patients were examined in the supine position, with their heads inclined at a $30^{\circ}$ angle. The transducer was covered in gel and gently placed externally upon the eyelid, avoiding excessive pressure. The flow velocity was measured in the vessels using a wall filter of $100 \mathrm{~Hz}$ and sample of $0.12 \mathrm{~mm}$. Doppler insonation angle was adjusted between 0 and $40^{\circ}$. After the waveforms were obtained, measurements of peak systolic velocity (PSV, $\mathrm{m} / \mathrm{sec}$ ), end diastolic velocity (EDV, $\mathrm{m} / \mathrm{sec}$ ) and the resistance index (RI) were calculated by automatic algorithm of the machine. Both eyes are examined, though single eye can be affected in few patients for comparison and screening. The parameters are peak systolic velocity, end diastolic velocity and resistive index in Central retinal artery and ophthalmic artery using Pulsed Doppler imaging.

Descriptive and inferential statistical analysis has been carried out in the present study. Results on continuous measurements are presented on Mean \pm SD (Min-Max) and results on categorical measurements are presented in Number (\%). Significance is assessed at 5\% level of significance. The Statistical software SPSS 15.0 was used for the analysis of the data and Microsoft word and Excel have been used to generate graphs, tables etc.

\section{Results}

Among the 60 patients, 36 patients were around the age 50-60 years. The PSV and EDV of the central retinal artery was found to be significantly lower in diabetic patients compared to controls regardless of retinopathy and a significant decrease in EDV and PSV of diabetic patients with retinopathy compared to diabetics without retinopathy was also found. The RI in the patients without diabetic retinopathy was significantly greater than that of normal subjects $(\mathrm{P}<0.001)$ and the RI in the patients with diabetic retinopathy $(0.81 \pm 0.04)$ was significantly greater $(\mathrm{P}<0.001)$ than that of normal subjects $(0.72 \pm 0.05)$ and of patients without diabetic retinopathy $(0.75 \pm$ 0.05). (Table 1)

Table 1: Comparison of Central Retinal Artery (CRA) parameters in three groups of patients studied

\begin{tabular}{|c|c|c|c|c|c|}
\hline $\begin{array}{c}\text { Retinal artery } \\
\text { parameters }\end{array}$ & Control Group & $\begin{array}{c}\text { Diabetic patients } \\
\text { without } \\
\text { retinopathy }\end{array}$ & $\begin{array}{c}\text { Diabetic patients } \\
\text { with diabetic } \\
\text { retinopathy }\end{array}$ & Total & P value \\
\hline PSV $(\mathrm{m} / \mathrm{sec})$ & $0.14 \pm 0.01$ & $0.12 \pm 0.02$ & $0.10 \pm 0.02$ & $0.12 \pm 0.02$ & $<0.001 * *$ \\
\hline $\mathrm{EDV}(\mathrm{m} / \mathrm{sec})$ & $0.04 \pm 0.01$ & $0.03 \pm 0.01$ & $0.02 \pm 0.01$ & $0.03 \pm 0.01$ & $<0.001^{* *}$ \\
\hline $\mathrm{RI}$ & $0.72 \pm 0.05$ & $0.75 \pm 0.05$ & $0.81 \pm 0.04$ & $0.76 \pm 0.06$ & $<0.001 * *$ \\
\hline
\end{tabular}

On comparing among the different groups, significant correlation was noted. (Table 2)

Table 2: Pair wise Comparison of Retinal artery parameters in three groups of patients studied

\begin{tabular}{|l|c|c|c|c|c|c|}
\hline \multirow{2}{*}{$\begin{array}{l}\text { Retinal artery } \\
\text { parameters }\end{array}$} & \multicolumn{2}{|c|}{ A vs B } & \multicolumn{2}{c|}{ A vs C } & \multicolumn{2}{c|}{ B vs C } \\
\cline { 2 - 7 } & Difference & P value & Difference & P value & Difference & P value \\
\hline PSV $(\mathrm{m} / \mathrm{sec})$ & 0.1758 & $<0.001^{* *}$ & 0.0375 & $<0.001^{* *}$ & 0.0200 & $<0.001^{* *}$ \\
\hline $\mathrm{EDV}(\mathrm{m} / \mathrm{sec})$ & 0.0083 & $<0.001^{* *}$ & 0.018 & $<0.001^{* *}$ & 0.0097 & $<0.001^{* *}$ \\
\hline RI & 0.028 & $0.020^{*}$ & 0.089 & $<0.001^{* *}$ & 0.062 & $<0.001^{* *}$ \\
\hline
\end{tabular}
A: Control group;
B: Diabetic patients without retinopathy;
C: Diabetic patients with retinopathy 


\section{JMSCR Vol||06||Issue ||05||Page 775-783||May}

In ophthalmic artery, the PSV values were significantly increased in diabetic patients compared to the normal group. EDV values did not show significant difference among three groups. The RI values of diabetic retinopathy

Table 3: Comparison of ophthalmic artery in three gr patients $(0.80 \pm 0.02)$ were significantly increased compared to non-retinopathy diabetics $(0.77 \pm 0.02)$ and also there was significant increase when compared to normal patients $(0.71 \pm 0.03)$. (Table 3)

\begin{tabular}{|l|l|l|l|l|l|}
\hline & Control Group & $\begin{array}{l}\text { Diabetic patients } \\
\text { without } \\
\text { retinopathy }\end{array}$ & $\begin{array}{l}\text { Diabetic patients } \\
\text { with diabetic } \\
\text { retinopathy }\end{array}$ & Total & P value \\
\hline $\mathrm{PSV}(\mathrm{m} / \mathrm{sec})$ & $0.31 \pm 0.03$ & $0.34 \pm 0.02$ & $0.35 \pm 0.01$ & $0.34 \pm 0.03$ & $<0.001^{* *}$ \\
\hline $\mathrm{EDV}(\mathrm{m} / \mathrm{sec})$ & $0.09 \pm 0.01$ & $0.08 \pm 0.01$ & $0.08 \pm 0.08$ & $0.08 \pm 0.05$ & 0.634 \\
\hline $\mathrm{RI}$ & $0.71 \pm 0.03$ & $0.77 \pm 0.02$ & $0.80 \pm 0.02$ & $0.76 \pm 0.05$ & $<0.001^{* *}$ \\
\hline
\end{tabular}

On comparing among the three different groups, significant correlation was noted in all the three groups in the PSV and RI values. (Table 4)

Table 4: Pair wise Comparison of OPHTHALMICARTERY in three groups of patients studied

\begin{tabular}{|l|l|l|l|l|l|l|}
\hline \multirow{2}{*}{ OPHTHALMICARTERY } & A vs B & A vs C & \multicolumn{2}{l|}{ B vs C } \\
\cline { 2 - 7 } & Difference & P value & Difference & P value & Difference & P value \\
\hline PSV $(\mathrm{m} / \mathrm{sec})$ & 0.028 & $<0.001^{* *}$ & 0.041 & $<0.001^{* *}$ & 0.013 & $0.011^{* *}$ \\
\hline EDV $(\mathrm{m} / \mathrm{sec})$ & 0.011 & 0.606 & 0.005 & 0.882 & 0.005 & 0.882 \\
\hline RI & 0.055 & $<0.001^{* *}$ & 0.090 & $<0.001^{* *}$ & 0.036 & $<0.001^{* *}$ \\
\hline
\end{tabular}

A: Control group; $\quad$ B: Diabetic patients without retinopathy; $\quad$ C: Diabetic patients with retinopathy

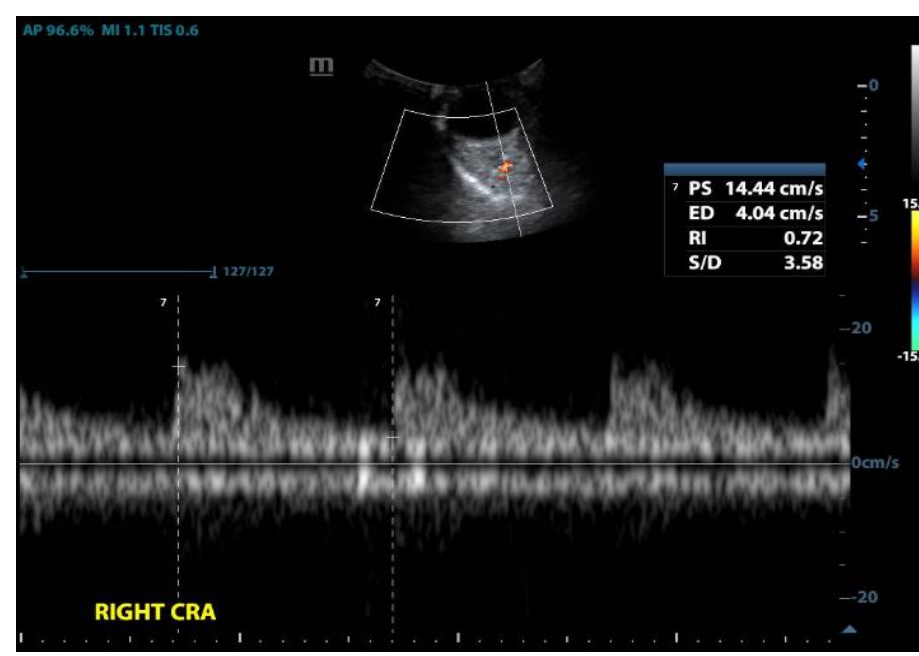

Fig 17 : Right Central Retinal Artery in Controls

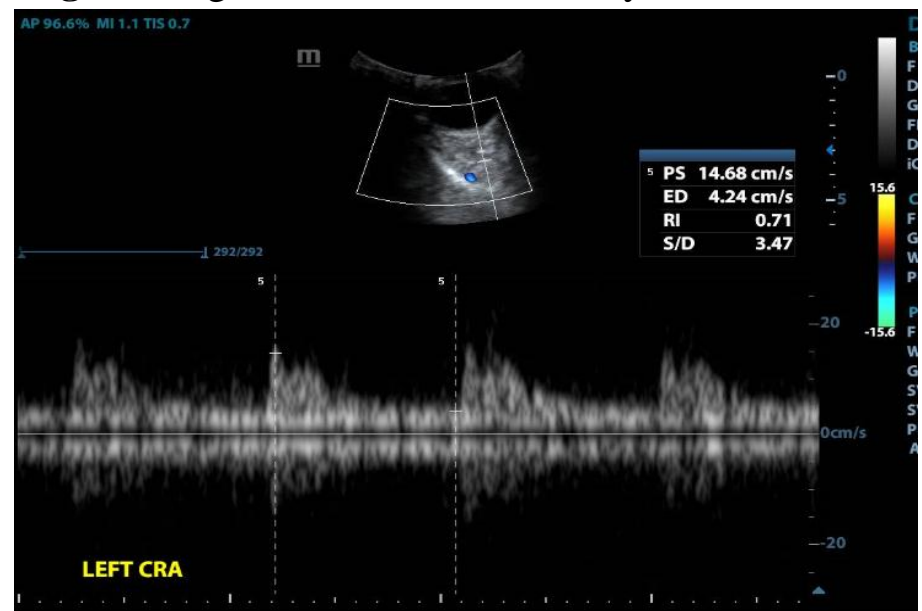

Fig 18 : Left Central Retinal Artery in Controls

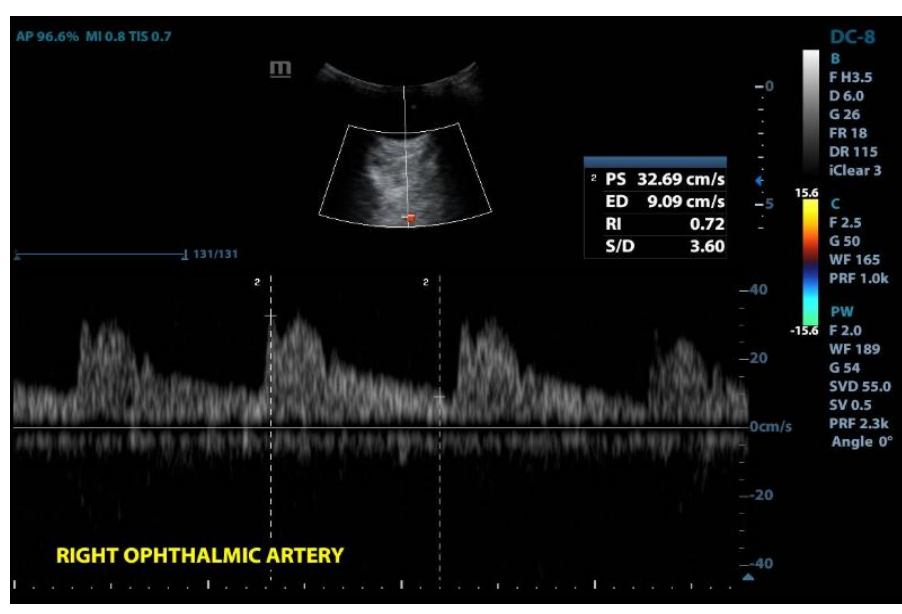

Fig 19 : Right Ophthalmic Artery in Controls

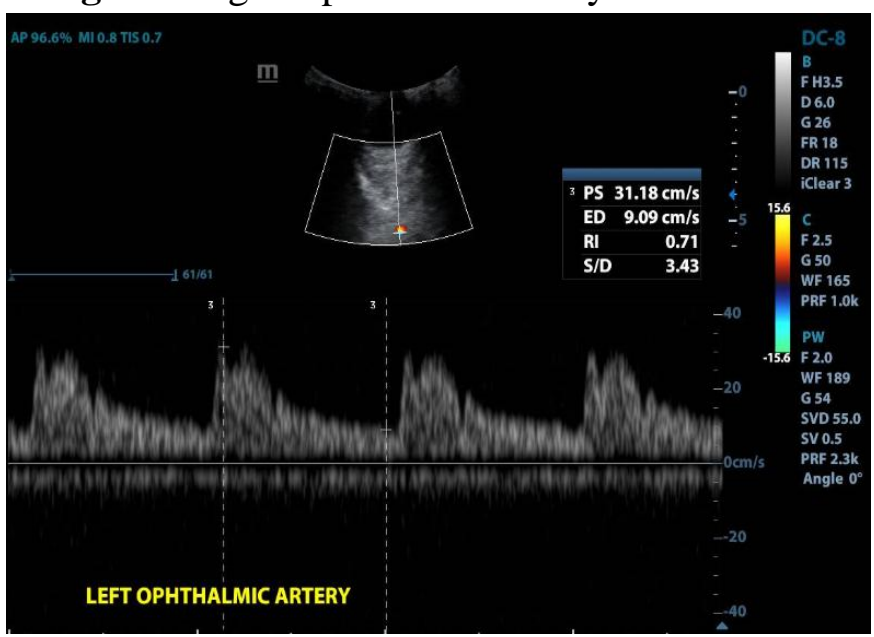

Fig 20 : Left Ophthalmic Artery in Controls 


\section{JMSCR Vol||06||Issue||05||Page 775-783||May}

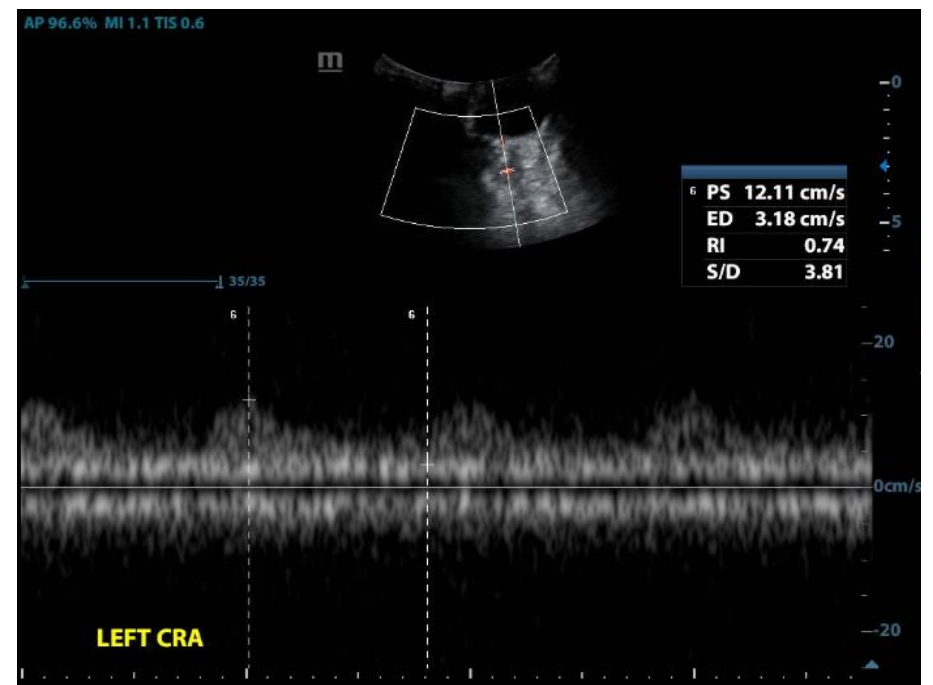

Fig 21 : Left Central Retinal Artery in Diabetics with no Retinopathy

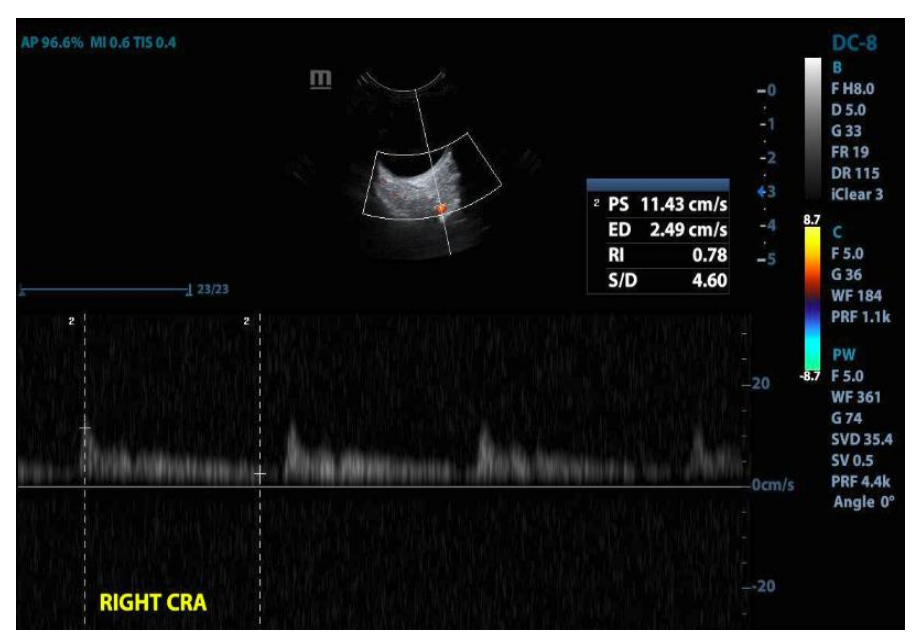

Fig 22 : Right Central Retinal Artery in Diabetics with Retinopathy

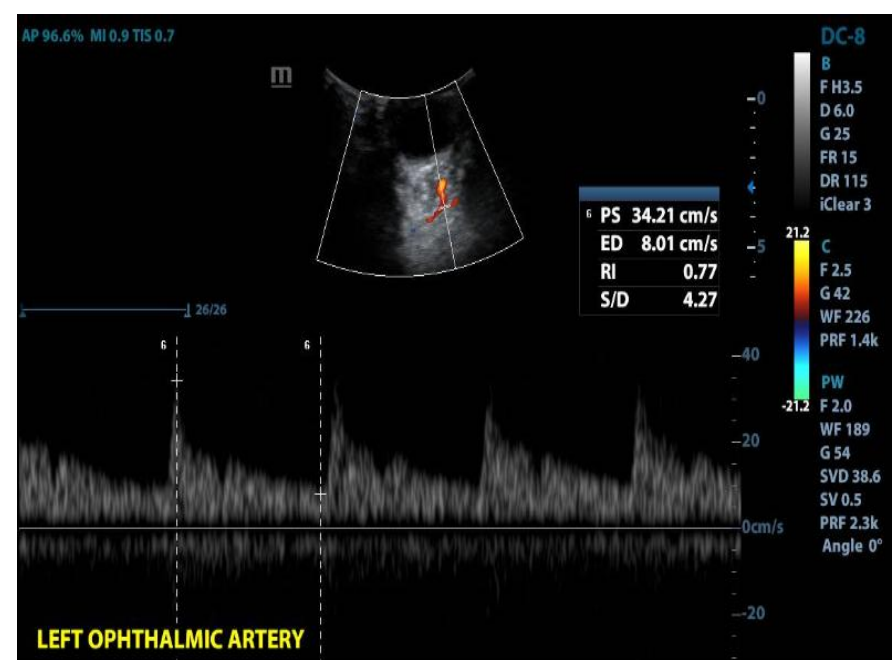

Fig 23: Left Ophthalmic Artery in Diabetics with no Retinopathy

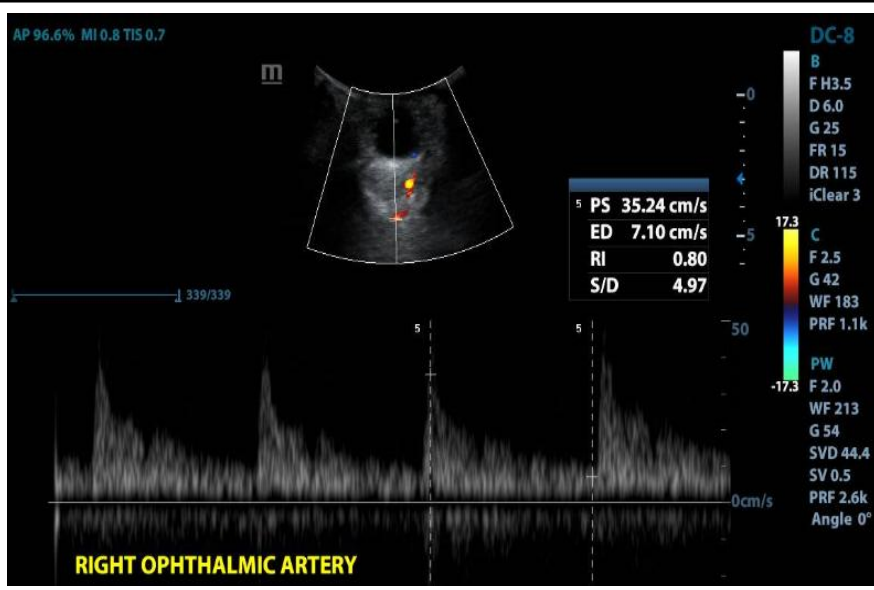

Fig 24: Right Ophthalmic Artery in Diabetics with Retinopathy

\section{Discussion}

Pulsed Doppler imaging has established itself a useful tool for evaluation of ocular hemodynamics in real time and physiological conditions. This modality is useful when standard procedures of diagnosis (fundus examination and fluorescein angiography) are difficult when there is cataract or vitreous haemorrhage. The other diagnostic methods which are used to measure the retinal circulation are blue light entotopic phenomenon, laser Doppler velocimetry and photo angiography. In our study we have compared diabetic patients with controls and found there was higher resistive index in ophthalmic artery and decreased velocities in central retinal artery among the diabetic patients. And the velocities were even decreased in CRA when we compared the diabetic retinopathy patients with no retinopathy diabetics. The resistive index of ophthalmic artery and velocity values of central retinal artery is strongly significant on comparing the patients with and without diabetic retinopathy with the control group. From the study, it was found that the arterial velocity in CRA decreases as severity of the disease increases. The results in this study matches to the study which was done by Goebel et al. (1995), in which he found the PSV and EDV of CRA to be significantly lower in diabetic retinopathy patients compared to the controls ${ }^{[5]}$. The patients who had PDR had decreased PSV compared to the BDR patients used in that study. However the velocity changes in ophthalmic 
artery and short posterior ciliary artery did not show significant changes and RI was not used as a parameter. There was a similar study by mendivil et al. (1995), which performed a study with 25 diabetes mellitus patients with PDR comparing them to 30 patients without diabetes. He found significant decrease in velocities of CRA and also in the velocities of ophthalmic artery. However non-proliferative retinopathy patients were not included in his study ${ }^{[6]}$. But in our study, we had significant increase in peak systolic velocity and no significant change in end diastolic velocity of ophthalmic arteries in diabetic groups when compared to the normal patients. An increase in the PSV coincides with rise of systolic blood pressure which was studied by Williamson et al. in 1995, however, in our study we did not confirm the results to this correlation in group analysis and there was not any significance in systolic blood pressure of our patients. Resistive index parameter was not used by the above mentioned studies on Colour Doppler imaging. Similar to our study, increased value of RI in ophthalmic artery was high lightened by Jane R. MacKinnon et al.2000 and the probable reason could be due to increase in PSV and decrease in EDV, but this is suggested as vascular changes in retinal and choroidal vasculature $^{[7]}$. It is estimated that retina receives only less than $10 \%$ of blood flow of the total ocular blood supply (Hart 1992), the remainder being directed to the choroid via the ciliary circulation. CDI has also provided some interesting information of changes in ocular blood flow velocities in patients after retinal laser treatment. Mendivil and Cuartero (1996) have reported on the CDI findings of diabetics with PDR after scatter laser photocoagulation ${ }^{[8]}$. Panretinal photocoagulation resulted in a reduction in the PSV of the OA compared to values before laser treatment. These results were obtained 6 months following treatment and did not change during 2 years of follow-up. Evans et al. (1997) also used CDI to investigate retrobulbar vascular reactivity in early diabetic retinopathy. In his study CDI of the ophthalmic artery and CRA was performed on 11 diabetic patients with no diabetic retinopathy and compared to 11 nondiabetic controls. While under conditions of isocapnic hyperoxia, diabetic patients exhibited a significantly lower resistance index in both the ophthalmic artery and CRA compared to controls. Hypoxia also induced an increased EDV in the CRA and decreased PSV in the ophthalmic artery compared to normal subjects. There is conflicting evidence, whether blood flow velocity increases or decreases in diabetic retinopathy. Different techniques and sites of measurement have provided varying results.

Using laser Doppler velocimetry Patel et al. (1992) showed an increased blood flow velocity in temporal retinal veins in diabetics with untreated retinopathy compared to non-diabetics and diabetic patients with no retinopathy. In contrast, Feke et al. (1994) studied blood speeds were on average $33 \%$ lower using laser Doppler measurements from the temporal retinal arteries in diabetics with NDR or BDR. The finding of decreasing velocities in CRA of diabetics, which becomes progressively lower as severity of retinopathy increases is likely to have a significant effect on retinal perfusion and function. Harris et al. (1996) showed that hyperoxia improves contrast sensitivity in patients with retinopathy in early stages, indicating possibility of a link between tissue hypoxia and visual function in diabetics. As it is not possible to accurately measure the diameter of the vessels being studied with this technique, blood flow cannot be quantitatively calculated and the closer relationship between blood velocity and volume flow in the vessels which is studied is unknown.

In Our findings, the reduced velocities in the CRA of diabetics should be interpreted with caution. As vascular studies involving diabetics with vasoactive medication may become a confounding variable. As it is not possible to quantitatively measure blood flow in the ocular vasculature accurately, the pathogenesis of diabetic retinopathy is still unclear. 


\section{Limitations}

A single observer for measurement of the Doppler indices to assess the hemodynamic changes, hence the measurement values could vary from user to user or even by the same user over time. The inclusion of posterior ciliary artery in assessing the hemodynamic changes would have been a supportive result. Much more specific age group of patients could have been helpful in finding the changes occurring at specific age. We have also ruled out the conditions like glaucoma and hypertension, those with history of smoking and previous history of intraocular surgery which are factors in causing ocular vasculopathy. Finding the hemodynamic changes between diabetic retinopathy patients among the different grades could have helped in finding the progression of vasculopathy.

\section{Conclusion}

Pulsed Doppler imaging is a useful modality to assess the risk of developing proliferative diabetic retinopathy which can lead on to visual loss. In pulsed Doppler imaging there was significant decrease in blood flow velocity of CRA of diabetic patients and it was much more reduced on comparing it with diabetic patients with retinopathy. The RI values of ophthalmic artery were also found to be increased in diabetic patients. Although the assessment of orbital blood flow in retinopathy requires further investigations, based on the results of our study we suggest pulsed Doppler imaging has the ability to provide information about hemodynamic changes and for the diagnosis diabetic retinopathy patients it can be used as a supportive modality.

\section{References}

1. The Lancet, Volume 382, Issue 9906, Page 1680, 23 November 2013.

2. Klein R, Klein Be, Moss Se, Davis Md, Demets Dl.The Wisconsin Epidemiologic Study Of Diabetic Retinopathy. Ii. Prevalence And Risk Of Diabetic Retinopathy When Age At Diagnosis Is
Less Than 30 Years. Arch Ophthalmol 1984; $102:$ 520-6.

3. Klein R, Klein Bek, Moss Se, Davis Md, Demets Dl. The Wisconsin Epidemiologic Study Of Diabetic Retinopathy Iii. Prevalence And Risk Of Diabetic Retinopathy When Age At Diagnosis Is 30 Or More Years.Arch Ophthalmol 1984; 102: 527-32.

4. Wild S, Roglic G, Green A, Sicree R, King H. Global Prevalence Of Diabetes, Estimates For The Year 2000 And Projections For 2030. Diabetes Care2004; $27: 1047-53$.

5. Goebel $\mathrm{W}^{1}$, Lieb We, Ho A, Sergott Rc, Farhoumand R, Grehn F. Color Doppler Imaging: A New Technique To Assess Orbital Blood Flow In Patients With Diabetic Retinopathy. Invest Ophthalmol Vis Sci. 1995 Apr;36(5):86470.

6. Mendívil A, Cuartero V, Mendívil Mp Ocular Blood Flow Velocities In Patients With Proliferative Diabetic Retinopathy And Healthy Volunteers: A Prospective Study. British Journal Of Ophthalmology 1995;79:413-416.

7. Jane R. Mackinnon ${ }^{1}$, Graham Mckillop ${ }^{2}$, Colm O'brien ${ }^{1}$, Kenneth Swa ${ }^{1}$, Zahida Butt $^{1}$ And Patricia Nelson ${ }^{1}$. Colour Doppler Imaging Of The Ocular Circulation In Diabetic Retinopathy. Acta Ophthalmic Scandinavia 2000.

8. Mendivil Antonio Md; Cuartero, Victoria Md. Ocular Blood Flow Velocities In Patients With Proliferative Diabetic Retinopathy After Scatter Photocoagulation: Two Years Of FollowUp. Retina: 1996.

9. Vi. The Arteries.3a. 4.The Internal Carotid Artery. Gray, Henry 191. Anatomy Of The Human Body.[Internet]. [Cited 2012 Aug 6]. Available From: Http://Www.Bartleby.Com/107/146.Html 
10. Schneider Pa, Rossman Me, Bernstein Ef E Al. Noninvasive_ Assessment Of Cerebral Collateral Blood Supply Through The Ophthalmic Artery. Stroke 1991;22:31-6.

11. Hayreh Ss, Dass R. The Central Retinal Artery Of The Retina I. Origin And Course. Brit. J. Ophthal. 1960; 44: 193.

12. Expert Committee On The Diagnosis And Classification Of Diabetes Mellitus. Report Of The Expert Committee On The Diagnosis And Classification Of Diabetes Mellitus. Diabetes Care 1997;20:11831197.

13. Genuth S, Alberti Kg, Bennett P, Buse J, Defronzo R, Kahn R, Kitzmiller J,Knowler Wc, Lebovitz H, Lernmark A, Nathan D, Palmer J, Rizza R,Saudek C, Shaw J, Steff es M, Stern M, Tuomilehto J, Zimmet P, Expert Committee On The Diagnosis And Classification Of Diabetes Mellitus2, The Expert Committee On The Diagnosis And Classification Of Diabetes Mellitus. Follow-Up Report On The Diagnosis Of Diabetes Mellitus. Diabetes Care 2003;26:3160-3167

14. International Expert Committee. International Expert Committee Report On The Role Of The A1c Assay In The Diagnosis Of Diabetes. Diabetes Care 2009; 32:1327-1334.

15. Preferred Practice Patterns, Diabetic Retinopathy, America Academy Of Ophthalmology 2008. Http://One.Aao.Org/Ce/Practiceguidelines/ Ppp_Content.Aspx?Cid=D0c853d3-219f487b-A524-326ab3cecd9a

16. Brett J. Rosenblatt And William E. Benson Diabetic Retinopathy Yanoff \& Duker: Ophthalmology, 3rd Ed. Http://Www.Mdconsult.Com/Das/Book/P df/282715756-3/978-0-323-04332-8/4U1.0-B978-0-323- 04332- 8..000925..Docpdf.Pdf?Isbn=978-0-323-04332-
8\&Eid=4-U1.0-B978-0-323-04332-

8..00092-5..Docpdf

17. Resnikoff S, Pascolini D, Etya'ale D, Kocur I, Pararajasegaram R, Pokharel Gp, Mariotti Sp. Global Data On Visual Impairment In The Year 2002. Bull World Health Organ. 2004 Nov;82(11):84451.Epub 2004 Dec14.

18. Basic And Clinical Science Course, Section 12: Retina And Vitreous Aao, 2011-2012.

19. The Effect Of Intensive Diabetes Treatment On The Progression Of Diabetic Retinopathy In Insulin-Dependent Diabetes Mellitus, The Diabetes Control And Complications Trial Research Group, Arch Ophthalmol. 1995; 113:36-51

20. Klein R, Klein Be, Moss Se, Davis Md, Demets Dl. The Wisconsin Epidemiologic Study Of Diabetic retinopathy: Ii. Prevalence And Risk Of Diabetic Retinopathy When Age At Diagnosis Is Less Than 30 Years. Archophthalmol 1984b; 102:520. PubMed PMID: 6367724.

21. The Diabetes Control And Complications Trial Research Group. The Effect Of Intensive Treatment Of Diabetes On Thedevelopment And Progression Of Long-Term Complications In InsulinDependent Diabetes Mellitus. N Engl J Med1993; 329:977. PubMed PMID: 8366922.

22. Frank Rn. Diabetic Retinopathy. N Engl J Med 2004; 350:48. PubMed PMID: 14702427.

23. Aiello Lm. Perspectives On Diabetic Retinopathy. Am J Ophthalmol 2003; 136:122. PubMed PMID: 12834680.

24. Wani Js, Nasti Ar, Ashai M, Keng M, Qureshi T, Rashid S. Incidence Of Maculopathy In Non-Proliferative Andproliferative Diabetic Retinopathy. JkPractitioner 2003; 10(4):275-278.

25. Tight Blood Pressure Control And Risk Of Macrovascular And Microvascular 
Complications In Type 2 Diabetes: Ukpds38. Uk Prospective Diabetes Study Group.Bmj 1998; 317:703. PubMed PMID:9732337.

26. Early Treatment Diabetic Retinopathy Study Research Group. Treatment Techniques And Clinical Guidelines For Photocoagulation Of Diabetic Macular Edema. Early Treatment Diabetic Retinopathy Study Report Number 2. Ophthalmology 1987;94:761-74. PubMed PMID: 3658348.

27. Mohamed Q, Gillies Mc, Wong Ty. Management Of Diabetic Retinopathy: A Systematic Review. Jama 2007; 298:902. PubMed PMID: 17712074.

28. Photocoagulation Treatment Of Proliferative Diabetic Retinopathy. Clinical Application Of Diabetic Retinopathy Study (Drs) Findings, Drs Report Number 8. The Diabetic Retinopathy Study Research Group. Ophthalmology1981; 88:583. PubMed PMID 7196564.

29. Photocoagulation Treatment Of Proliferative Diabetic Retinopathy: The Second Report Of Diabetic Retinopathy Study Findings. Ophthalmology 1978; 85:82. PubMed PMID: 345173.

30. Friedman, Neil J And Peter K Kaiser. The Massachusetts Eye And Ear Infirmary Illustrated Manual Of ophthalmology, 3rd Ed. Saunders Elsevier, 2009.

31. Meredith Ta. The Diabetic Vitrectomy Study. In: Kertes C, Ed. Clinical Trials In Ophthalmology-A Summary And Practice Guide. 1998: 37-48.

32. Lang J \& Kageyama I (1990): The Ophthalmic Artery And Its Branches, Measurements Andclinical Importance. Surg Radiol Anat 12:83-90

33. Lieb We, Cohen Sm, Merton Da, Schieldsja, Mitchell Dg \& Goldberg Bb
(1991):Color Doppler Imaging Of The Eye And Orbit:Technique And Normal Vascular Anatomy .Arch Ophthalmol 109: 527-531.

34. Gosling Rg \& King Dh (1974): Arterial Assessment By Doppler-Shift Ultrasund. Proc R Soc Med 67: 447-449.

35. Rojanapongpun P, Morrison B, Drance Sm. Reproducibility Of Transcranial Doppler Ultrasound Examinations Of The Ophthalmic Artery Flow Velocity. Br J Ophthalmol 1993;77:22-4.

36. Rojanapongpun P, Drance Sm. Velocity Of Ophthalmic Arterial Flow Recorded Doppler Ultrasound In Nomal Subjects. Am J Ophthalmol 1993:7(5):639-47.

37. Kouvidis Gk, Benos A, Kyriakopoulou G, Anastopoulos G, Triantafyllou D. Colour Doppler Ultrasonography Of The Ophthalmic Artery: Flow Parameters In Normal Subjects. The Significance Of The Resistve Index. Int Angiol. 2000 Dec; 19(4) : 319-25.

38. Oliveira Ca De, Sa Ram De, Velarde Lgc, Monteiro Vnp, Neto Hc. Doppler Velocimetry Of The Ophthalmiuc Artery Reproducibility Of Blood Flow Velocity Measurements. Jun. 2012 Jun 1;31(6): 879-84. 